\title{
Title: Rivaroxaban plasma levels in acute ischemic stroke and intracerebral hemorrhage
}

$\underline{\text { Running title: Rivaroxaban plasma levels in acute stroke }}$

David J. Seiffge ${ }^{\mathrm{a}}$, MD; Georg Kägi ${ }^{\mathrm{b}}$, MD; Patrik Michel ${ }^{\mathrm{c}}$, MD; Urs Fischer ${ }^{\mathrm{d}}$, MD; Yannick Béjot $^{\mathrm{e}}, \mathrm{PhD}$; Susanne Wegener ${ }^{\mathrm{f}}$, MD; Marialuisa Zedde ${ }^{\mathrm{g}}, \mathrm{MD}$; Guillaume Turc ${ }^{\mathrm{h}}, \mathrm{PhD}$; Charlotte Cordonnier ${ }^{\mathrm{i}}, \mathrm{PhD}$; Peter S. Sandor ${ }^{\mathrm{j}}, \mathrm{MD}$; Gilles Rodier ${ }^{\mathrm{k}}$, MD; Andrea Zini ${ }^{1}, \mathrm{MD}$; Manuel Cappellari ${ }^{\mathrm{m}}$, MD; Sabine Schädelin ${ }^{\mathrm{n}}, \mathrm{MSc}$; Alexandros A. Polymeris ${ }^{\mathrm{a}}, \mathrm{MD}$; David Werring $^{\mathrm{o}} \mathrm{PhD}, \mathrm{FRCP}$; Sebastian Thilemann ${ }^{\mathrm{a}}, \mathrm{MD}$; Ilaria Maestrini ${ }^{\mathrm{i}}, \mathrm{MD}$; Eivind Berge ${ }^{\mathrm{p}}, \mathrm{PhD}$; Christopher Traenka ${ }^{\mathrm{a}}$, MD; Jochen Vehoff ${ }^{\mathrm{b}}$, MD; Gian Marco De Marchis ${ }^{\mathrm{a}}$, MD, MSc; Monika Kapauer ${ }^{\mathrm{b}}$, MD, Nils Peters ${ }^{\mathrm{a}, \mathrm{s}}$, MD; Gaia Sirimarco ${ }^{\mathrm{c}}, \mathrm{MD}, \mathrm{PhD}$; Leo H. Bonati ${ }^{\mathrm{a}}$, MD; Marcel Arnold ${ }^{d}$, MD; Philippe A. Lyrer ${ }^{\mathrm{a}}$, MD; Emmanuel De Maistre ${ }^{\mathrm{q}}$, MD, Andreas Luft ${ }^{\mathrm{f}}$, MD; Dimtrios A. Tsakiris ${ }^{\mathrm{r}}$, MD; Stefan T. Engelter ${ }^{\mathrm{a}, \mathrm{s}}$, MD on behalf of the NOACISP study group

a) Stroke Center and Department of Neurology, Department of Clinical Research, University Hospital and University of Basel, Switzerland

b) Department of Neurology, Kantonsspital St. Gallen, Switzerland

c) Department of Neurology, University Hospital, Lausanne, Switzerland

d) Department of Neurology, Inselspital Bern, Switzerland

e) Department of Neurology, Dijon Stroke Registry, University Hospital, Dijon, France

f) Department of Neurology, University Hospital Zurich, Switzerland

g) Neurology Unit-Stroke Unit, Arcispedale Santa Maria Nuova-IRCCS, Reggio Emilia, Italia

h) Department of Neurology, Sainte-Anne Hospital, INSERM U894, Paris, France

i) University of Lille, INSERM U1171, Degenerative \& vascular cognitive disorders, CHU Lille, Department of Neurology, Lille, France

j) Department of Neurology, Kantonsspital Baden, Switzerland

k) Departement of Neurology, Centre Hospitalier Annecy Genevois, France

1) Stroke Unit, Department of Neuroscience, S'Agostino-Estense Hospital, Modena University Hospital, Italy

m) USD Stroke Unit, DAI di Neuroscienze, Azienda Ospedaliera Universitaria Integrata, Verona, Italy

This article has been accepted for publication and undergone full peer review but has not been through the copyediting, typesetting, pagination and proofreading process which may lead to differences between this version and the Version of Record. Please cite this article as an 'Accepted Article', doi: 10.1002/ana.25165 
n) Clinical Trial Unit, University Hospital Basel, Switzerland

o) Stroke Research Center, Department of Brain Repair and Rehabilitation, UCL Institute of Neurology and The National Hospital for Neurology and Neurosurgery, Queen Square, London, United Kingdom

p) Departments of Internal Medicine and Cardiology, Oslo University Hospital, Oslo,

Norway

q) Haematological Laboratory, University Hospital, Dijon, France

r) Diagnostic Hematology, University Hospital Basel, Basel, Switzerland

s) Neurorehabilitation Unit, University Center for Medicine of Aging and Rehabilitation Basel, Felix Platter Hospital, University of Basel, Switzerland

Corresponding author:

David Seiffge

Stroke Center and Neurology

University Hospital Basel and University Basel

Petersgraben 4

4031 Basel, Switzerland

Tel: 0041-61-3287278

Email: david.seiffge@usb.ch

Word count:

Title: 81 characters

Running title: 36 characters

Abstract: 250

Introduction: 397

Discussion: 1410

Total word count (not including abstract or references, figure legends, etc.): 3170

References: 30

Figures: 3

Tables: 1

Online supplemental material: 3 tables 


\section{Abstract}

Objective:

Information about Rivaroxaban plasma levels (RivLev) may guide treatment decisions in patients with acute ischemic stroke (AIS) and intracerebral hemorrhage (ICH) taking rivaroxaban.

\section{Methods:}

In a multicenter registry-based study (Novel-Oral-Anticoagulants-In-Stroke-Patients collaboration;NOACISP;ClinicalTrials.gov:NCT02353585) of patients with stroke while taking rivaroxaban, we compared RivLev in patients with AIS and ICH. We determined how many AIS-patients had RivLev $\leq 100 \mathrm{ng} / \mathrm{ml}$, indicating possible eligibility for thrombolysis and how many ICH-patients had RivLev $\geq 75 \mathrm{ng} / \mathrm{ml}$, possibly eligible for the use of specific reversal agents. We explored factors associated with RivLev (Spearman correlation; regression models) and studied the sensitivity and specificity of INR-thresholds to substitute RivLevs using cross tables and ROC curves.

\section{Results:}

Among 241 patients (median age 80 years[IQR73-84], median time-from-onset-to-admission 2 hours[IQR1-4.5hours], median RivLev 89ng/ml[31-194]), 190 had AIS and 51 had ICH. RivLev were similar in AIS-patients (82ng/ml[IQR30-202] and ICH-patients (102ng/ml[IQR 51-165]; $\mathrm{p}=0.24)$. Trough $\operatorname{RivLev}_{(\leq 137 \mathrm{ng} / \mathrm{ml})}$ occurred in 126/190 (66.3\%) AIS- and 34/51 (66.7\%) ICH-patients. Among AIS-patients, 108/190 (56.8\%) had RivLev $\leq 100 \mathrm{ng} / \mathrm{ml}$. In ICHpatients 33/51(64.7\%) had RivLev $\geq 75 \mathrm{ng} / \mathrm{ml}$. RivLev were associated with rivaroxaban dosage, inversely with renal function and time-since-last-intake (each $\mathrm{p}<.05$ ). INR $\leq 1.0$ had a specificity of $98.9 \%$ and a sensitivity of $25.7 \%$ to predict RivLev $\leq 100 \mathrm{ng} / \mathrm{ml}$. INR $\geq 1.4$ had a sensitivity of $59.3 \%$ and specificity of $90.1 \%$ to predict RivLev $\geq 75 \mathrm{ng} / \mathrm{ml}$.

\section{Interpretation:}

RivLev did not differ between patients with AIS and ICH. Half of the patients with AIS under Rivaroxaban had RivLev low enough to consider thrombolysis. In ICH-patients, 2/3 had RivLev high enough to meet the eligibility for the use of a specific reversal agent. INRthresholds perform poor to inform treatment decisions in individual patients. 
Journal Subject Codes: [44] Acute Cerebral Infarction [70] Anticoagulants [185] intracranial hemorrhage; other anticoagulants; Plasma Levels
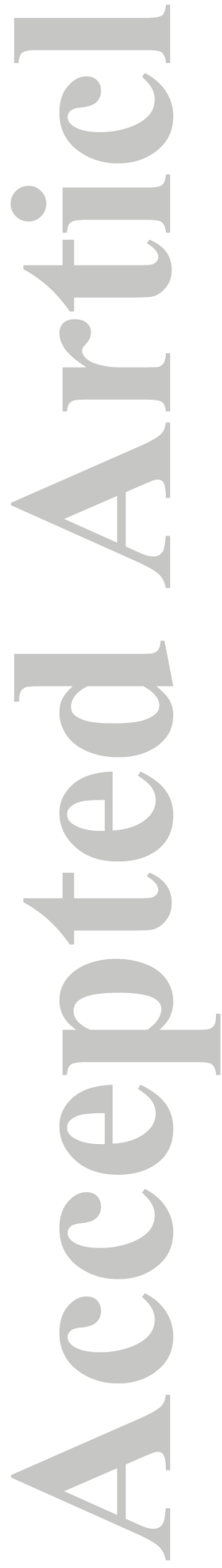


\section{Introduction}

Rivaroxaban is an inhibitor of factor $\mathrm{Xa}$ in the coagulation cascade with rapid onset of the anticoagulant effect ${ }^{1}$. The peak plasma levels are expected 2-6 hours after intake while trough levels occur after 10-14 hours ${ }^{2,3}$. However, these figures were based on measurements in healthy volunteers or patients with deep venous thrombosis rather than acute stroke. Furthermore, plasma levels might be influenced by factors like impaired renal function, advanced age and concomitant medication ${ }^{2,4}$ and inter-individual variance can be large ${ }^{2,4}$.

Assessing the anticoagulant effect of rivaroxaban is challenging as its influence on standard coagulation tests is limited ${ }^{5}$. More recently, drug-specific coagulation tests measuring rivaroxaban plasma levels (RivLev) have been available ${ }^{6}$. Measuring the anticoagulant activity of rivaroxaban in individual patients with acute ischemic stroke (AIS) and acute intracerebral hemorrhage $(\mathrm{ICH})$ may influence treatment decisions to use or refrain from thrombolysis $^{7,8}$ or specific reversal agents ${ }^{9,10}$.

However, there exists considerable clinical uncertainty around patients taking rivaroxaban presenting with AIS or ICH regarding acute treatment decisions as the anticoagulant activity in individual patients is often not known which might lead to delayed or denied treatment options.. Measurement of RivLev may show if AIS have low RivLev, while patients with ICH have high RivLev but it remains to be clarified whether there is an association between RivLev and type of stroke. . It is unknown, how many AIS-patients may possibly qualify for thrombolysis and how many ICH-patients possibly meet the eligibility criteria for treatment with specific reversal agents if RivLev were taken into account. It is also unclear whether in AIS and ICH patients RivLev might be associated with clinical characteristics, such as renal function. Finally, if measurement of RivLev is not available, it remains unknown whether 
INR is a sufficiently accurate substitute of RivLev to inform therapeutic decisions in individual patients.

In this large, international multi-center collaboration we have therefore analyzed RivLev in patients with AIS or ICH using rivaroxaban to answer the following questions: 1) Does the distribution of RivLev differ between patients with AIS and those with ICH? 2) How many AIS-patients had RivLev $\leq 100 \mathrm{ng} / \mathrm{ml}$, indicating being possibly eligible for thrombolysis and how many ICH-patients had RivLev $\geq 75 \mathrm{ng} / \mathrm{ml}$, meeting the eligibility criteria for the use of specific reversal agents. 3) How is RivLev influenced by renal function, time-since-lastintake, dosage of rivaroxaban, age or sex? 4) Can the INR be used to estimate RivLev and inform clinical decisions?

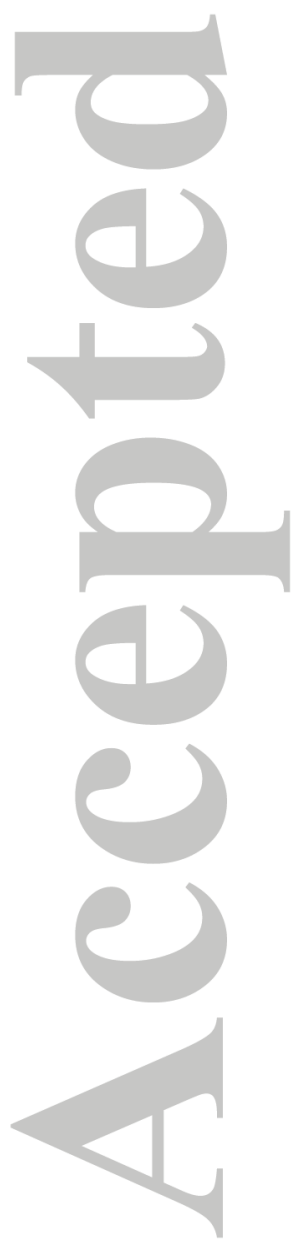




\section{Methods}

\section{Study}

Study design and study population

We performed a cohort study at centers participating in the international, multicenter Novel Oral Anticoagulants in Stroke Patients (NOACISP) collaboration ${ }^{11}$. Data from local registries were used to identify patients with AIS or ICH who were treated with rivaroxaban at the time of stroke onset and who had RivLev measured on hospital admission. Details on participating centers, number of patients contributed, type of registry and recruitment period are summarized in supplemental table 1.

\section{Ethics}

The NOACISP registry as a multicenter collaboration (ClinicalTrials.gov: NCT02353585) was approved by the ethics committee in Basel, Switzerland (EKNZ 2014-027). The requirement for additional local ethical approval differed among participating centers and was acquired by the local principal investigator if necessary.

\section{$\underline{\text { Data collection }}$}

Data were collected as in prior published research studies ${ }^{11}{ }^{12}$ : Briefly, local investigators filled in standardized forms with predefined variables ${ }^{11-14}$ using individual patient data from local prospective registries. Completed forms were collected at the coordinating center in Basel, where the pooled analysis was performed. The corresponding author had full access to all the data in the study and takes responsibility for its integrity and the data analysis.

\section{$\underline{\text { Baseline and follow-up data }}$}


The following baseline variables were recorded: age, sex, stroke severity on admission as assessed by the National Institutes of Health Stroke Scale (NIHSS) ${ }^{15}$, location of ICH (deep or lobar) and time-since-last-intake (i.e. time of last intake to time of stroke center admission), symptom onset and time of hospital admission.

The following risk factors were collected, applying definitions used in prior research ${ }^{11-14}$ : atrial fibrillation, hypertension, diabetes mellitus, hypercholesterolemia, coronary artery disease, previous use of antiplatelet drugs, antihypertensive drugs or statins.

Measurement of drug specific rivaroxaban plasma levels and laboratory measures

All coagulation tests including RivLev were performed as part of routine assessment in participating centers. Blood draw for all laboratory tests were done immediately after admission and admission time was taken as the time point of RivLev measurement as done in prior research ${ }^{16}$. All centers used commercially available assays to determine RivLev (DiXal, Hyphen-Biomed, France was used by the following centers: Basel, Paris, Zürich, Baden, St. Gallen, Verona, Lausanne, Bern, Reggio Emilia; Liquid anti-Xa Stago, Asnières, France used by: Dijon, Lille, Annecy; and Hemosil liquid anti Xa, IL Werfen, US by the center in Modena). We applied the following definitions for different RivLev categories, which had been reported for patients using $20 \mathrm{mg}$ of rivaroxaban once daily ${ }^{2}: \operatorname{RivLev}_{\text {trough }} \leq 137 \mathrm{ng} / \mathrm{ml}$,

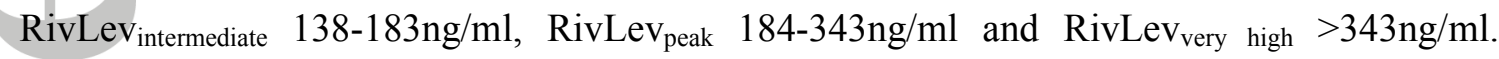
Additionally, we used 2 cut-off values with potential clinical implications: I) RivLev $\leq 100 \mathrm{ng} / \mathrm{ml}$, a threshold previously suggested ${ }^{7}$ and applied ${ }^{11,17}$ to select patients taking rivaroxaban for thrombolysis and II) RivLev $\geq 75 \mathrm{ng} / \mathrm{ml}$, the lowest threshold applied in the pivotal trial on andexanet alpha ${ }^{10}$, a targeted reversal agent for rivaroxaban, to select patients with a relevant concentration of rivaroxaban suitable for effective use of this specific reversal agent. We then calculated the number of patients eligible from our cohort for I) thrombolysis (RivLev $\leq 100 \mathrm{ng} / \mathrm{ml}$ ) using the INR-threshold with the highest specificity (assuming clinicians 
chose the maximum of safety) and II) andexanet treatment (RivLev $>75 \mathrm{ng} / \mathrm{ml}$ ) using the INRthreshold with the highest Youden-Index (Specificity+Sensitivity-1) for a maximum of effectiveness.

Furthermore, we collected data on standard laboratory measurements of INR (central lab measurement) and renal function as quantified by the glomerular filtration rate (GFR) estimated by CKD-EPI equation as done in prior stroke research ${ }^{12,18}$.

\section{$\underline{\text { Statistics }}$}

Group comparison between patients with AIS and those with ICH were performed using the $\chi 2$ test for categorical variables and the Mann-Whitney U-test for continuous variables. Correlations were tested with Spearman test.

Univariate linear censored regression models (Tobit models ${ }^{19}$ ) were constructed with RivLev as dependent parameter. Age, sex, time-since-last -intake (continuous variable), renal function (continuous variable), dosage of rivaroxaban, type of stroke (AIS vs ICH) and NIHSS were included as independent parameters. RivLev was left-censored at detection level $(20 \mathrm{ng} / \mathrm{ml})$ and $\log$ transformed prior to analysis. The estimates and $95 \% \mathrm{CI}$ are presented back transformed to the original scale therefore indicating an approximatively multiplicative effect.

To assess the accuracy of the INR to identify RivLev of $\leq 100 \mathrm{ng} / \mathrm{ml}$ and $\geq 75 \mathrm{ng} / \mathrm{ml}$, ROC curves were constructed and the area under the curve (AUC) was calculated. Sensitivity and specificity of the different INR cut-offs $(\leq 1.0, \leq 1.1, \leq 1.2$ and $\leq 1.4$ for $\leq 100 \mathrm{ng} / \mathrm{ml}$ and $\geq 1.0$, $\geq 1.1, \geq 1.2$ and $\geq 1.4$ for $\geq 75 \mathrm{ng} / \mathrm{ml}$ ) were calculated using cross tables.

All tests were 2-tailed, and statistical significance was determined at $\alpha$-level of 0.05 . Statistical analyses were performed using SPSS, version 23.0, for Windows and $\mathrm{R}^{20}$. 


\section{Results}

\section{Study population:}

Our study population comprised 241 patients with AIS $(n=190)$ or ICH $(n=51)$. The median delay between AIS or ICH onset and admission was 2.0 hours (IQR 1.0-4.5 hours). In 187 patients $(77.6 \%)$, the last intake of rivaroxaban was within 24 hours before admission and in another $36(14.9 \%)$ the last intake was within 48 hours before admission. In the remaining 18 patients $(7.5 \%)$, the last intake was $>48$ hours before admission or unknown.

\section{$\underline{\text { Baseline characteristics }}$}

Baseline characteristics for all patients are displayed in table 1. The majority of patients in both cohorts - AIS and ICH - took 20mg of rivaroxaban per day (AIS: 113 patients [59.8\%] vs. ICH: 36 patients [69.2\%], p>0.05). Patients with AIS had more often hypercholesterolemia $(\mathrm{p}<0.001)$ and a trend to receive more often treatment with statins $(\mathrm{p}=0.06)$ compared to those with ICH. Patients with ICH had higher baseline NIHSS $(p<0.001)$ compared to those with AIS. In 27 of 51 ICH-patients $(52.9 \%)$ the location of the ICH was lobar and in 24 of $51(47.1 \%)$ deep.

\section{$\underline{\text { Rivaroxaban plasma levels (RivLev) }}$}

The median RivLev was similar in patients with AIS (82ng/ml, IQR 30-202ng/ml) and those with ICH (102ng/ml, IQR 51-165ng/ml, p=0.24).

Distribution of different RivLev categories is displayed in figure 1. The majority of patients had RivLev ${ }_{\text {trough }(\leq 137 \mathrm{ng} / \mathrm{ml})}$ in both groups with no statistical significant difference (AIS: 126 patients [66.3\%] vs. ICH: 34 patients [66.7\%], $\mathrm{p}=0.36$ for all different categories). The proportions of patients with $\operatorname{RivLev}_{\text {peak(184-343ng/ml) }}$ (AIS: 39 patients [20.5\%] vs. ICH: 10 patients [19.6\%]) or RivLev very $\operatorname{high}(>343 \mathrm{ng} / \mathrm{ml})$ (AIS: 14 patients [7.4\%] vs. ICH: 1 patient 
$[2.0 \%])$ were also comparable in the two groups. $18.6 \%$ of patients presenting $>12$ hours after

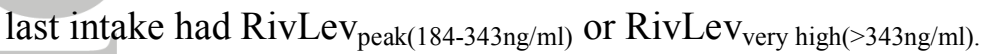

Overall, 133 of 241 patients (55.2\%) had RivLev $\leq 100 \mathrm{ng} / \mathrm{ml}$ (AIS: 108 of 190 patients [56.8\%] and ICH: 25 of 51 patients [49.0\%]). In turn, 136 of 241 patients $(56.4 \%)$ had RivLev $\geq 75 \mathrm{ng} / \mathrm{ml}$ (AIS: 103 of 190 patients [54.2\%] and ICH: 33 of 51 patients [64.7\%]). In

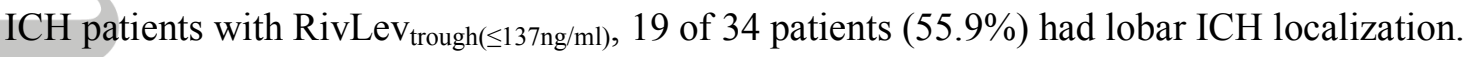

Factors associated with RivLev: Correlation of times since last intake and renal function, dosage but not age and sex

Across all patients, we observed a significant correlation between RivLev and dosage (Spearman $\mathrm{Rho}=.15, \mathrm{p}=0.024$, figure $2 \mathrm{~A}$ ) and inverse correlations with time-since-last-intake (Spearman Rho $=-.25, \mathrm{p}<0.001$, figure $2 \mathrm{~B})$ and renal function $($ Spearman $\mathrm{Rho}=-.13, \mathrm{p}=0.050$, figure 2C).

In Tobit regression analysis, we found significant associations between RivLev and daily rivaroxaban dosage (regression coefficient 1.04 [1.02-1.08], $\mathrm{p}=0.027$ ), renal function (regression coefficient of 0.99 [0.98-0.99], $\mathrm{p}=0.025$ ) and time-since-last-intake (regression coefficient of 0.98 [0.98-0.99], $\mathrm{p}=0.0002)$. There was no statistical significant association with age, sex, type of stroke (AIS vs ICH) or NIHSS on admission.

\section{$\underline{\text { RivLev and INR }}$}

We observed a correlation between RivLev and INR (Spearman Rho $=.66, \mathrm{p}<.001$, figure 2D). Overall, predictive ability of the INR was good with an AUC of 0.830 (95\%CI 0.773 to 0.888, figure 3a) for RivLev $\leq 100 \mathrm{ng} / \mathrm{ml}$ and 0.843 (95\% CI 0.786 to 0.899 , figure $3 \mathrm{~b}$ ) for

RivLev $\geq 75 \mathrm{ng} / \mathrm{ml}$. The sensitivity to predict RivLev $\leq 100 \mathrm{ng} / \mathrm{ml}$ with $\mathrm{INR} \leq 1.0 / \leq 1.1 / \leq 1.2 / \leq 1.4$ was $25.7 \% / 42.9 \% / 74.3 \% / 90.5 \%$ and specificity was $98.9 \% / 89.4 \% / 83.0 \% / 55.3 \%$. The 
sensitivity to predict RivLev $\geq 75 \mathrm{ng} / \mathrm{ml}$ with $\mathrm{INR} \geq 1.0 / \geq 1.1 / \geq 1.2 / \geq 1.4$ was $100 \% / 97.5 \% / 89.0 \% / 59.3 \%$ while the specificity was $4.9 \% / 39.5 \% / 59.3 \% / 90.1 \%$.

Cross tables indicating true and false negative and positive according to different INR thresholds are displayed in online supplemental figure 1.

Using INR thresholds to select patients for clinical decisions would result in the following eligibility of patients among our study population: the INR $\leq 1.0$ threshold with the highest specificity yielding a maximum of safety, results in only 27 of 105 patients $(25.7 \%)$ with RivLev $\leq 100 \mathrm{ng} / \mathrm{ml}$ being eligible for thrombolysis. The INR-threshold of INR $\geq 1.4$ to select patients with the maximum of efficacy for andexanet treatment, results in 70 of 118 patients (59.3\%) with RivLev $\geq 75 \mathrm{ng} / \mathrm{ml}$ being eligible for effective rivaroxaban reversal.

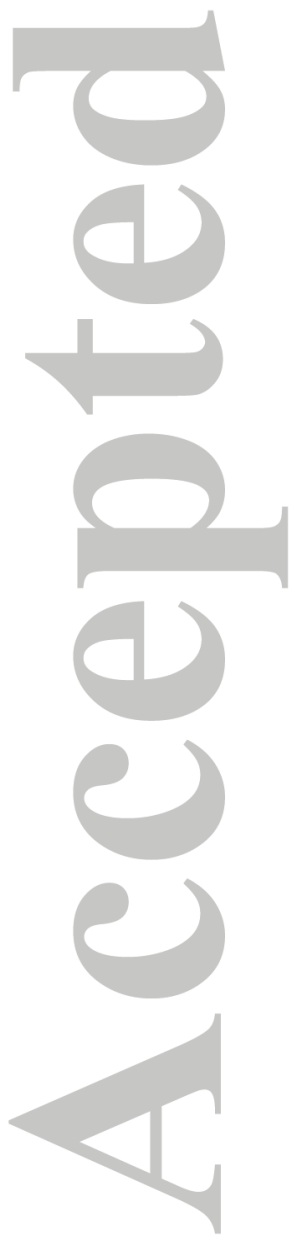




\section{Discussion}

This multi-center, international observational study yields the following key findings: 1) RivLev did not differ between patients with AIS and ICH taking rivaroxaban In both, AIS and ICH patients, $2 / 3$ of patients have low RivLev while $1 / 4$ of patients have high RivLev. 2) RivLev seem useful for the decision whether to use or refrain from thrombolysis or specific reversal agents as thrombolysis would possibly be allowed in $56.8 \%$ of patients with AIS otherwise not eligible for thrombolysis while only $64.7 \%$ of patients with ICH possibly qualify for effective reversal agent treatment. 3) Measured RivLev were associated with rivaroxaban dosage and inversely with renal function and time-since-last-intake. 4) RivLevs were associated with the INR but our data do not support the use of INR as a substitute to RivLev to inform treatment decisions in individual patients.

Counterintuitively, RivLev do not differ between AIS and ICH patients taking rivaroxaban with low RivLev present in $2 / 3$ of the AIS - as well as the ICH patients. The high percentage of low RivLev among AIS patients is analogous to similar findings among VKA-patients ${ }^{21}$. Here, subtherapeutic INR values were associated with an increased risk of AIS ${ }^{21}$, indicating that insufficient anticoagulant effects may have contributed to or triggered the ischemic stroke in patients with both types of anticoagulants. Interestingly, more than $1 / 4$ of the ischemic stroke patients had their stroke at peak or even higher RivLev. Whether this is due to noncardioembolic stroke etiologies needs to be analyzed in further studies.

(

While the risk of intracerebral hemorrhage in patients taking VKA is associated with higher INR-values (in particular $>3.0)^{21,22}$, about $2 / 3$ of our ICH patients had low RivLev. This seeming discrepancy finding suggests that $\mathrm{ICH}$ in patients taking Rivaroxaban is not 
necessarily promoted by high or peak drug levels. Our results suggest the importance of additional mechanisms other than a direct vaso-noxious effect of anticoagulants ${ }^{23}$ like the underlying vessel disease that will lead to the bleeding. Over half of the ICH patients with low RivLev had lobar ICH, possibly indicating the presence of an underlying cerebral amyloid angiopathy which might explain why these patients bled despite relatively low RivLev.

Two-thirds of patients with AIS had low RivLev with potentially clinical implications. More than half of these patients had RivLev $<100 \mathrm{ng} / \mathrm{ml}$ and would be potentially eligible for thrombolysis. These patients would be ineligible for thrombolysis without RivLev measurement as to current guidelines ${ }^{8}$. Our data show that excluding categorically all patients taking rivaroxaban from intravenous thrombolysis seems not justified as a majority of these patients would be possibly eligible.

Likewise, two-thirds of patients with ICH had low RivLev, which means that not all patients with ICH may necessarily require the use of a reversal agent like andexanet alfa. In the study on andexanet alfa ${ }^{10}$, a recombinant modified human factor Xa decoy protein, 20 of 67 patients that received andexanet were excluded from the efficacy population analysis due to baseline RivLev $<75 \mathrm{ng} / \mathrm{ml}^{10}$. Transferring this cut-off to our study population, 18 of 51 patients with ICH (35\%) had RivLev of $<75 \mathrm{ng} / \mathrm{ml}$ on admission and would thus not qualify for effective andexanet alfa treatment. Thus, a potentially unnecessary overuse might be an issue if andexanet is to be given to all patients irrespective of its actual anticoagulant activity.

This means that measuring RivLev in patients with AIS and ICH has the potential to guide individual treatment decisions. Although, commercial assays for RivLev measurement are available they are yet lacking broad availability. The idea that results in clinical practice are not available fast enough to guide clinical decisions is widespread. Nevertheless, it has been 
shown that results can be obtained within around 30 minutes $^{16}$, . Thus, , the development of specific point-of-care devices for NOAC including rivaroxaban (e.g. Clincialtrials.gov: NCT02825394) can lead to a shorter time-to-treatment in patients with stroke under rivaroxaban. If they prove to be reliable and gain market authorization, they will make measurement of RivLev broadly available and more rapid. Given that $2 / 3$ of ICH patients have elevated RivLev making them eligible for reversal agent treatment, one can argue that in all ICH patients taking rivaroxaban treatment should be given without any delay of waiting for RivLev measurement. A similar approach might be imaginable for the use of thrombolysis in those AIS patients, otherwise eligible for thrombolysis.

Taking into account the limitations of our study, in particular the purely observational design, the currently limited evidence of the thresholds used, the limited information about potential confounders (e.g. presence versus absence of amyloid angiopathy) we are cautious regarding conclusions for clinical practice. There is not sufficient certainty with regard to safety as to recommend treating patients with AIS with thrombolysis or ICH-patients with reversal agents, irrespectively of the RivLev, although such scenarios might evolve in the future.

The RivLev suggesting safe thrombolysis (i.e. $<100 \mathrm{ng} / \mathrm{ml}$ ) in AIS differs from the RivLev meeting the eligibility criteria for reversal in the scenario of ICH $(\geq 75 \mathrm{ng} / \mathrm{ml})$. Interestingly, a similar gap exists also in patients on VKA for whom thrombolysis is regarded as safe if the INR is $<1.7$ in patients with AIS $^{24}$ while in the scenario of ICH associated with VKA, rapid correction of the INR is warranted if INR is $>1.2^{25,26}$.

In patients taking rivaroxaban for treatment of deep vein thrombosis, RivLev is modulated by time-since-last-intake, dosage of rivaroxaban and renal function ${ }^{2}$. Our data add to these findings that the same variables are also the key factors influencing RivLev in patients with AIS or ICH under rivaroxaban. 
RivLey correlated well with INR-values in our population, confirming recent research findings ${ }^{27,28}$. In addition, we tested the sensitivity and specificity of the INR to predict two clinically important RivLev thresholds: To identify patients with RivLev $\leq 100 \mathrm{ng} / \mathrm{ml}$ for thrombolysis $^{7,17}$ - assuming that the avoidance of bleeding complications has the highest priority - an INR $\leq 1.0$ showed the maximum of safety. Nevertheless, this threshold results in the exclusion of $3 / 4$ of patients eligible based on RivLev. To identify patients with RivLev $>75 \mathrm{ng} / \mathrm{ml}^{10}$ suitable for effective Rivaroxaban reversal, a threshold of $\mathrm{INR} \geq 1.4$ showed optimal performance. Using this threshold, only $59 \%$ of patients eligible based on RivLey would be identified. Thus, although overall correlation between INR and RivLev is good, our data do not support the use of INR to inform therapeutic decisions in individual patients.

Our study has the following strengths: 1) To the best of our knowledge, we report on the largest yet available dataset of patients with acute ischemic stroke or intracerebral hemorrhage and measured rivaroxaban plasma levels. 2) The data from the participating centers were extracted from prospective registries that are ascertained independently from the current research questions, which is an argument against bias. 3) In our study, the mean time delay between symptom onset and admission to a participating center was only 2 hours. This short delay is an advantage as the measured RivLev are likely to reflect the RivLev in the patient at symptom onset. 4) Furthermore, we report on a comprehensive dataset including clinical data, RivLey and other laboratory analysis.

Nevertheless, our study has the following limitations: 1) Although we report on a relatively large dataset, the overall numbers are still insufficient for multivariable analysis. 2) Measurement of RivLev was not standardized throughout all center and different calibrators 
and assays were used. Nevertheless, all these assays/calibrators are licensed and certified. 3) In our analysis, we used the threshold of $\geq 75 \mathrm{ng} / \mathrm{ml}$ for the use of specific reversal agents as this threshold was used in the pivotal trial on andexanet alpha ${ }^{10}$. Nevertheless, this may be considered arbitrary and other thresholds such as $50 \mathrm{ng} / \mathrm{ml}^{29}$ or even lower ${ }^{9}$ have been proposed. 4) Although the threshold of $<100 \mathrm{ng} / \mathrm{ml}$ to select patients for thrombolysis is reported in literature ${ }^{7}$, the clinical evidence for this approach is limited. This cut-off is based on theoretical considerations on available pharmacokinetic data on rivaroxaban ${ }^{2}$. First clinical data $^{11,17,30}$ suggest that this threshold might be clinically useful although it is still to be considered arbitrary because confirmative studies are currently missing. 5) Nearly half of the patients in this study are from one single center which might affect generalizability.

In conclusion, our data indicate that in a substantial number of patients with AIS thrombolysis may be safely applicable while a substantial number of patients with ICH may not meet the eligibility criteria for the use of specific reversal agents. RivLevs are dependent on timesince-last-intake, dosage of rivaroxaban and renal function. Although INR correlates well with RivLev, our data do not support the use of INR to substitute RivLev to inform treatment decisions in individual patients.

\section{Acknowledgement:}

DJS was supported by a fellowship for young researches from the Science Funds of the University Hospital Basel.

The NOACISP registry was supported by grants from the Swiss Heart Foundation and the Science Funds [Wissenschaftsfonds] of the University Hospital Basel.

\section{Author's contribution:}

DS, STE and DAT conceived the study. DS, SS and STE drafted the manuscript.

All authors contributed to the design of the study, collection and interpretation of the data and editing the manuscript. 


\section{Potential Conflicts of Interest:}

DJS: Scientific advisory boards: Bayer and Pfizer. Compensation for educational efforts: Stago. "Thrombosis Research Award 2017”: Bayer Foundation.

GK: Scientific advisory boards: Bayer, Boehringer Ingelheim

YB: Speacker or consulting fees: Daiichi-Sankyo, Pfizer, BMS, and Bayer.

SW: research funds: Boehringer Ingelheim.

CC: Scientific Advisory boards: Bayer, Daiichi-Sankyo (fees paid to ADRINORD, no personal funding)

AZ: speaker fees and consulting fees: Boehringer-Ingelheim, Scientific advisory board: Daiichi Sankyo and Boehringer-Ingelheim.

GMDM: Travel honoraria: Bayer; speaker honoraria: BMS/Pfizer.

NP: travel honoraria: Boehringer-Ingelheim. Scientific advisory board: Bayer, BoehringerIngelheim and BMS/Pfizer. Funding: Bayer, Boehringer-Ingelheim, BMS/Pfizer.

GS: Scientific advisory boards: Daiichi-Sankyo.

LHB: consultancy and advisory board fees: Bayer and BMS.

MA: speaker honoraria: Bayer and Boehringer Ingelheim. Scientific advisory board: Bayer, Boehringer Ingelheim, BMS, Pfizer and Daichy Sankyo

PAL: Scientific advisory boards: Bayer, Daiichi-Sankyo and Boehringer Ingelheim. Funding for travel or speaker honoraria: Bayer and Boehringer Ingelheim. Research funding: Boehringer Ingelheim,

DAT: Speaker honoraria and unrestricted educational grants: Bayer, Boeringer Ingelheim, Pfizer.

STE: Funding for travel or speaker honoraria: Bayer and Boehringer Ingelheim. Scientific advisory boards: Bayer, Boehringer Ingelheim, and BMS/Pfizer. Educational grant from Pfizer. Compensation for educational efforts: Stago

Bayer, Boerhinger Ingelheim, Bristol-Myers Squibb (BMS), Daiichi-Sankyo and Pfizer produce anticoagulants. Stago produces a calibrated anti-factor Xa-assay to measure Rivaroxaban Plasma Levels. The Bayer Foundation is linked to the Bayer AG, producer of anticoagulants.

UF, PM, MLZ, GT, PS, GR, MC, SS, AAP, DW, ST, IM, EB, CT, JV, MK, EDM, AL have no conflicts of interest. 
Figure 1: Distribution of rivaroxaban plasma levels in patients with ischemic stroke or intracerebral hemorrhage.

Figure 2: Correlation between rivaroxaban plasma levels and daily rivaroxaban dosage (A), time since last intake (B), renal function(C) and INR (D).

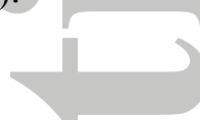

Figure 3: Receiver operating characteristic (ROC) curves to predict rivaroxaban plasma levels $\leq 100 \mathrm{ng} / \mathrm{ml}$ (A) and $\geq 75 \mathrm{ng} / \mathrm{ml}$ (B) using the International Normalized Ratio (INR) and specificity and sensitivity for different pre-defined thresholds.

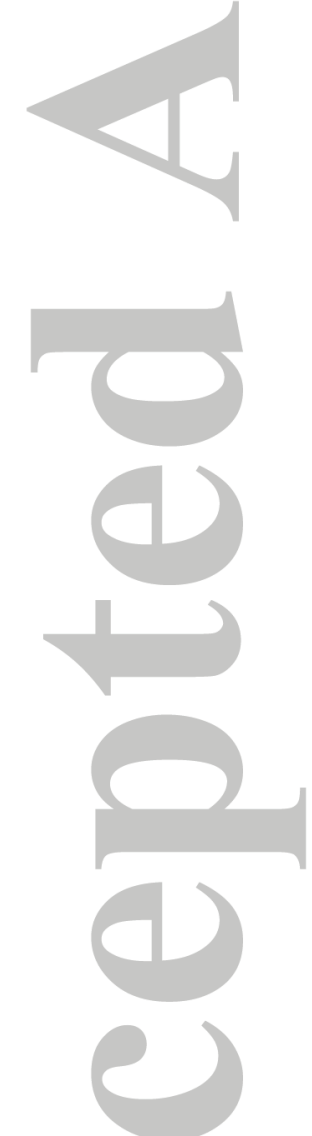




\section{References:}

1. Eriksson BI, Quinlan DJ, Eikelboom JW. Novel oral factor Xa and thrombin inhibitors in the management of thromboembolism. Annual review of medicine. 2011;62:41-57.

2. Mueck W, Lensing AW, Agnelli G, Decousus H, Prandoni P, Misselwitz F. Rivaroxaban: population pharmacokinetic analyses in patients treated for acute deep-vein thrombosis and exposure simulations in patients with atrial fibrillation treated for stroke prevention. Clinical pharmacokinetics. 2011 Oct;50(10):675-86.

3. Reilly PA, Lehr T, Haertter S, et al. The effect of dabigatran plasma concentrations and patient characteristics on the frequency of ischemic stroke and major bleeding in atrial fibrillation patients: the RE-LY Trial (Randomized Evaluation of Long-Term Anticoagulation Therapy). J Am Coll Cardiol. 2014 Feb 4;63(4):321-8.

4. Testa S, Tripodi A, Legnani C, et al. Plasma levels of direct oral anticoagulants in real life patients with atrial fibrillation: Results observed in four anticoagulation clinics. Thrombosis research. 2016 Jan;137:178-83.

5. Cuker A, Siegal DM, Crowther MA, Garcia DA. Laboratory measurement of the anticoagulant activity of the non-vitamin K oral anticoagulants. J Am Coll Cardiol. 2014 Sep 16;64(11):1128-39.

6. Harenberg J, Kraemer R. Measurement of the new anticoagulants. Thrombosis research. 2012 Apr;129 Suppl 1:S106-13.

7. Steiner T, Bohm M, Dichgans M, et al. Recommendations for the emergency management of complications associated with the new direct oral anticoagulants (DOACs), apixaban, dabigatran and rivaroxaban. Clinical research in cardiology : official journal of the German Cardiac Society. 2013 Jun;102(6):399-412.

8. Jauch EC, Saver JL, Adams HP, Jr., et al. Guidelines for the early management of patients with acute ischemic stroke: a guideline for healthcare professionals from the American Heart Association/American Stroke Association. Stroke. 2013 Mar;44(3):870-947.

9. Steiner T, Weitz JI, Veltkamp R. Anticoagulant-Associated Intracranial Hemorrhage in the Era of Reversal Agents. Stroke. 2017 May;48(5):1432-7.

10. Connolly SJ, Milling TJ, Jr., Eikelboom JW, et al. Andexanet Alfa for Acute Major Bleeding Associated with Factor Xa Inhibitors. N Engl J Med. 2016 Aug 30.

11. Seiffge DJ, Hooff RJ, Nolte CH, et al. Recanalization Therapies in Acute Ischemic Stroke Patients: Impact of Prior Treatment With Novel Oral Anticoagulants on Bleeding Complications and Outcome. Circulation. 2015 Sep 29;132(13):1261-9.

12. Gensicke H, Zinkstok SM, Roos $\mathrm{YB}$, et al. IV thrombolysis and renal function. Neurology. 2013 Nov 12;81(20):1780-8.

13. Engelter ST, Soinne L, Ringleb P, et al. IV thrombolysis and statins. Neurology. 2011 Aug 30;77(9):888-95.

14. Gensicke H, Strbian D, Zinkstok SM, et al. Intravenous Thrombolysis in Patients Dependent on the Daily Help of Others Before Stroke. Stroke. 2016 Feb;47(2):450-6.

15. Lyden P, Brott T, Tilley B, et al. Improved reliability of the NIH Stroke Scale using video training. NINDS TPA Stroke Study Group. Stroke. 1994 Nov;25(11):2220-6.

16. Seiffge DJ, Traenka C, Polymeris A, et al. Feasibility of rapid measurement of Rivaroxaban plasma levels in patients with acute stroke. Journal of thrombosis and thrombolysis. 2017 Jan;43(1):112-6.

17. Seiffge DJ, Traenka C, Gensicke H, et al. Intravenous thrombolysis in stroke patients receiving rivaroxaban. European journal of neurology : the official journal of the European Federation of Neurological Societies. 2014;21(1):e3-4.

18. Levey AS, Stevens LA, Schmid CH, et al. A new equation to estimate glomerular filtration rate. Ann Intern Med. 2009 May 05;150(9):604-12. 
19. Henningsen A. censReg: Censored Regression (Tobit) Models. R package version 0.526. 2017; Available from: https://CRAN.R-project.org/package=censReg.

20. Team RDC. R: A language and environment for statistical computing. Vienna, Austria.: R Foundation for Statistical Computing; 2008.

21. Mearns ES, White CM, Kohn CG, et al. Quality of vitamin K antagonist control and outcomes in atrial fibrillation patients: a meta-analysis and meta-regression. Thrombosis journal. 2014;12:14.

22. Dequatre-Ponchelle N, Henon H, Pasquini M, et al. Vitamin K antagonists-associated cerebral hemorrhages: what are their characteristics? Stroke. 2013 Feb;44(2):350-5.

23. Hart RG. What causes intracerebral hemorrhage during warfarin therapy? Neurology. 2000 Oct 10;55(7):907-8.

24. Demaerschalk BM, Kleindorfer DO, Adeoye OM, et al. Scientific Rationale for the Inclusion and Exclusion Criteria for Intravenous Alteplase in Acute Ischemic Stroke: A Statement for Healthcare Professionals From the American Heart Association/American Stroke Association. Stroke. 2016 Feb;47(2):581-641.

25. Hemphill JC, 3rd, Greenberg SM, Anderson CS, et al. Guidelines for the Management of Spontaneous Intracerebral Hemorrhage: A Guideline for Healthcare Professionals From the American Heart Association/American Stroke Association. Stroke. 2015 Jul;46(7):2032-60. 26. Steiner T, Al-Shahi Salman R, Beer R, et al. European Stroke Organisation (ESO) guidelines for the management of spontaneous intracerebral hemorrhage. Int J Stroke. 2014 Aug 24.

27. Ebner M, Birschmann I, Peter A, et al. Point-of-care testing for emergency assessment of coagulation in patients treated with direct oral anticoagulants. Critical care (London, England). 2017 Feb 15;21(1):32.

28. Ebner M, Peter A, Spencer C, et al. Point-of-Care Testing of Coagulation in Patients Treated With Non-Vitamin K Antagonist Oral Anticoagulants. Stroke. 2015 Oct;46(10):27417.

29. Levy JH, Ageno W, Chan NC, Crowther M, Verhamme P, Weitz JI. When and how to use antidotes for the reversal of direct oral anticoagulants: guidance from the SSC of the ISTH. Journal of thrombosis and haemostasis : JTH. 2016 Mar;14(3):623-7.

30. Seiffge DJ, Traenka C, Polymeris AA, et al. Intravenous Thrombolysis in Patients with Stroke Taking Rivaroxaban Using Drug Specific Plasma Levels: Experience with a Standard Operation Procedure in Clinical Practice. J Stroke. 2017 Sep;19(3):347-55. 


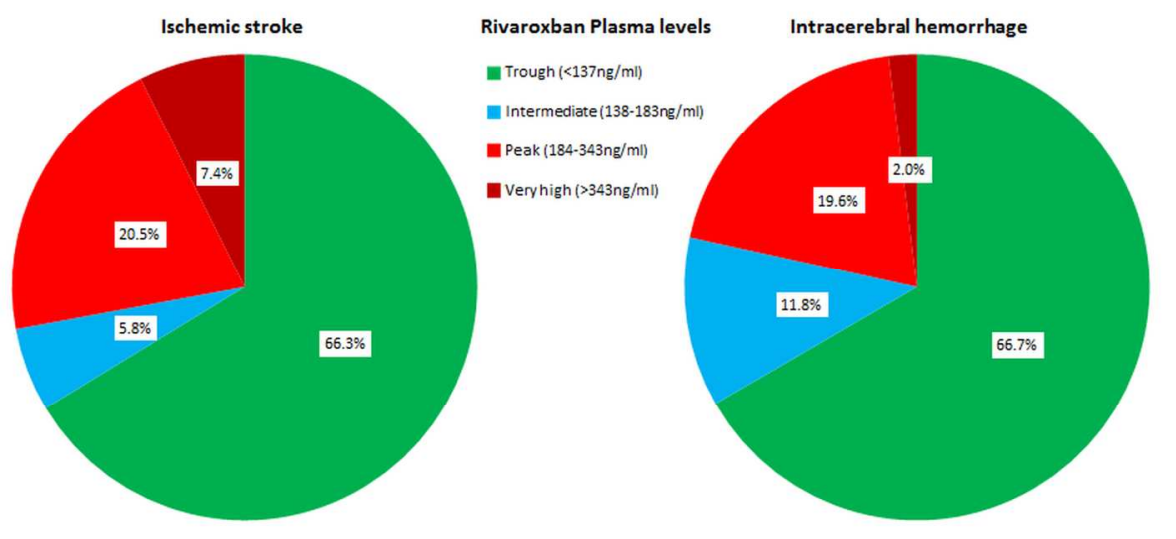

Figure 1 - color

$170 \times 70 \mathrm{~mm}(300 \times 300$ DPI $)$

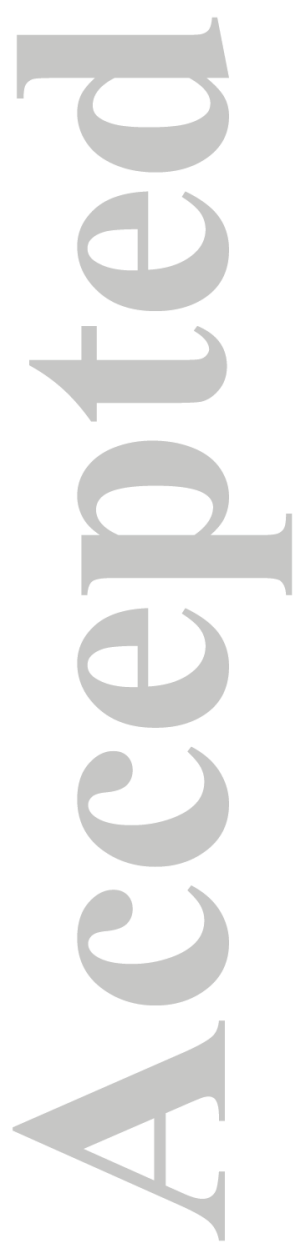

John Wiley \& Sons

This article is protected by copyright. All rights reserved. 


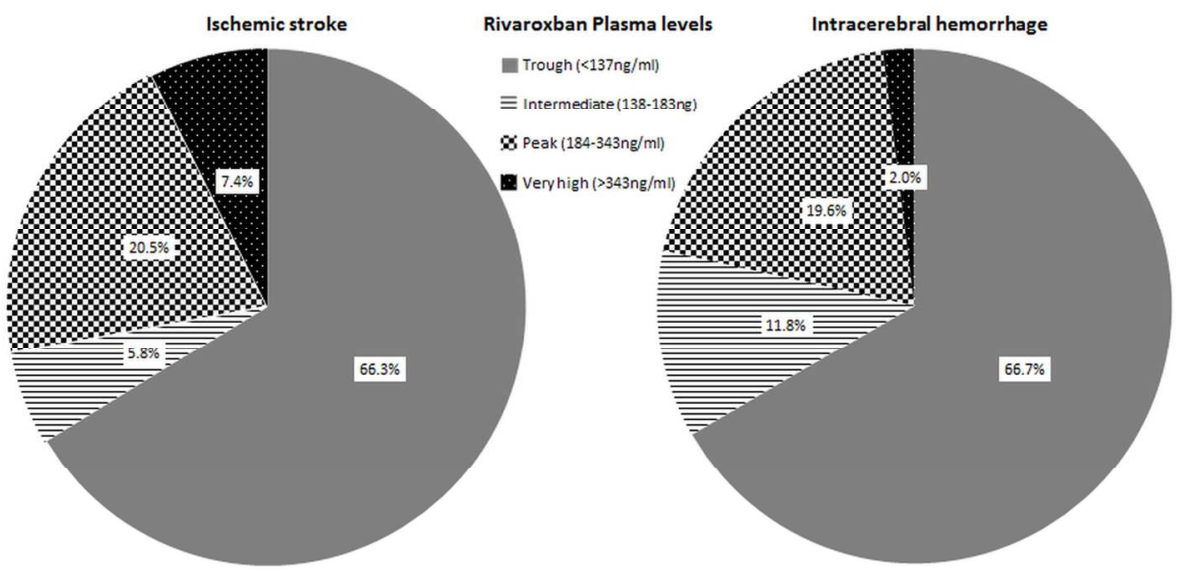

Figure 1 - no color

$170 \times 77 \mathrm{~mm}(300 \times 300$ DPI $)$

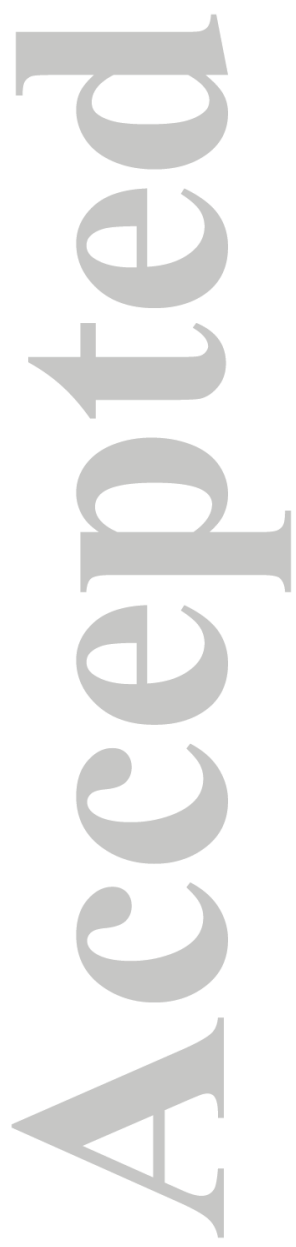

John Wiley \& Sons

This article is protected by copyright. All rights reserved. 

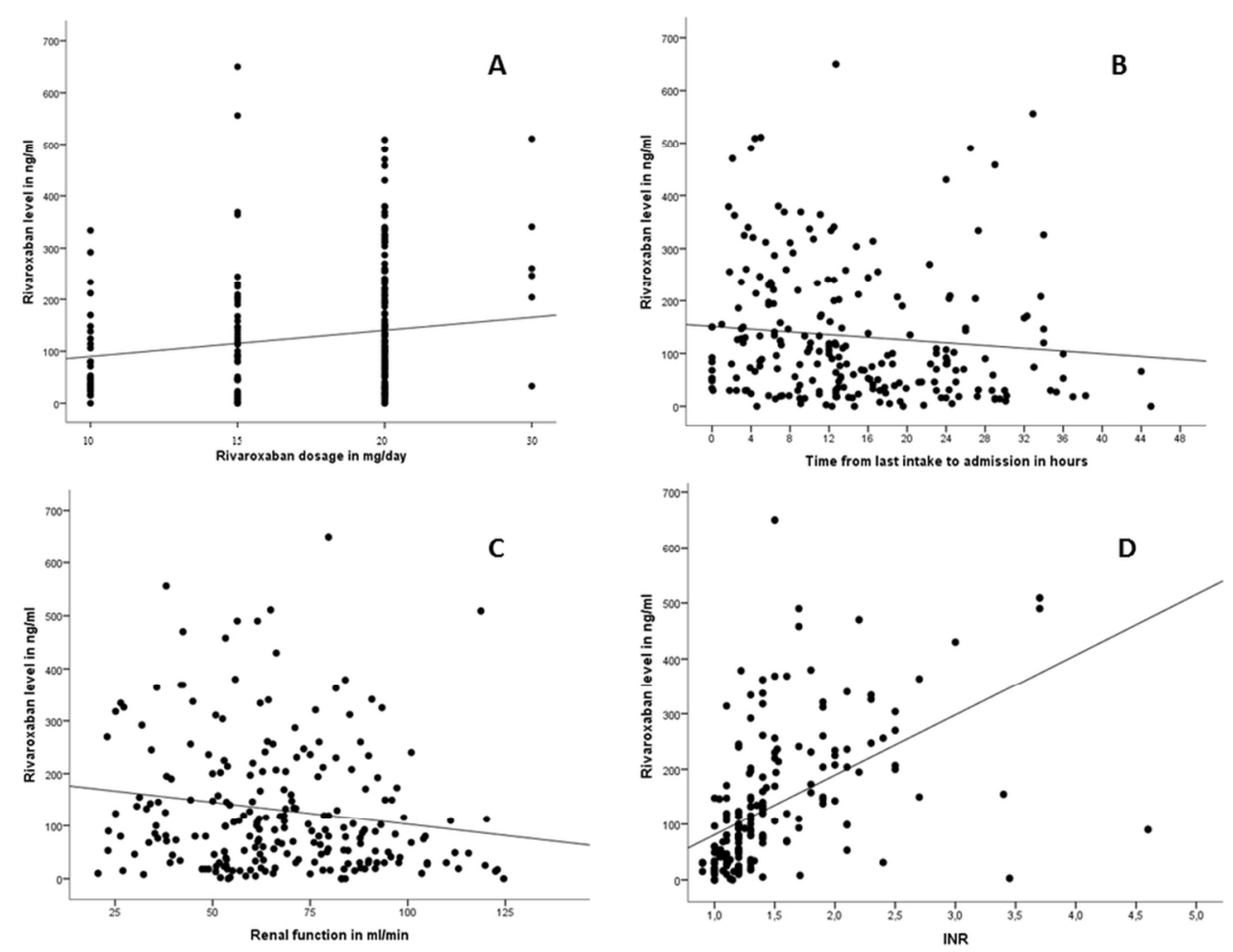

Figure 2

$170 \times 127 \mathrm{~mm}(300 \times 300 \mathrm{DPI})$ 

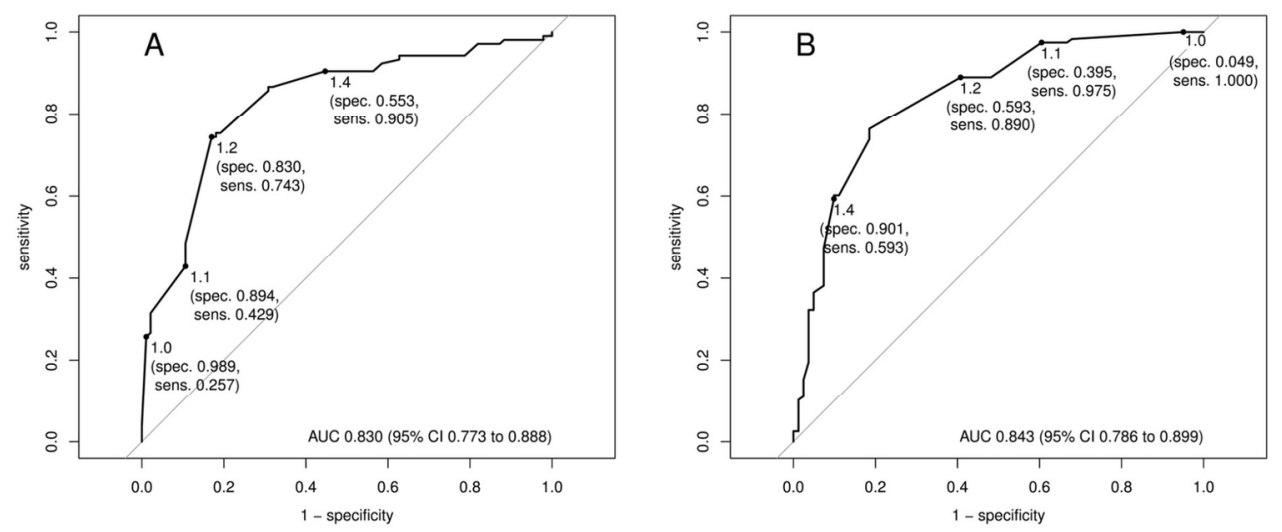

Figure 3

$72 \times 31 \mathrm{~mm}(600 \times 600 \mathrm{DPI})$

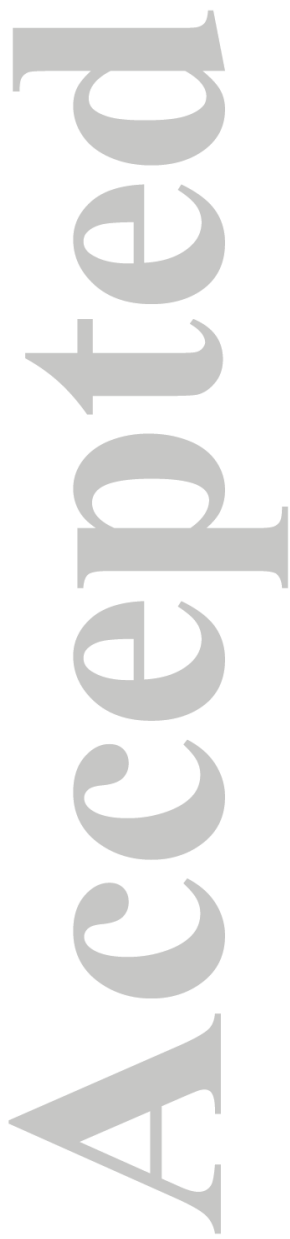

John Wiley \& Sons

This article is protected by copyright. All rights reserved. 


\section{Table:}

Table 1: Baseline characteristics of patients taking rivaroxaban

\begin{tabular}{|c|c|c|c|}
\hline (n) & $\begin{array}{l}\text { Ischemic stroke } \\
\mathrm{N}=190\end{array}$ & $\begin{array}{l}\text { Intracerebral hemorrhage } \\
\mathrm{N}=51\end{array}$ & $\mathrm{p}$ \\
\hline Age, years & $80(74-84)$ & $77(72-85)$ & ns \\
\hline Female sex & $98(51 \%)$ & $22(42 \%)$ & ns \\
\hline NIHSS score on admission & $8(2-13)$ & $12(4-19)$ & $<.001$ \\
\hline \multicolumn{4}{|l|}{ Details on timing and dosage } \\
\hline Time from event to admission, hours & $2.2(1.0-4.1)$ & $1.7(0.3-4.9)$ & ns \\
\hline Time from last-intake to admission, hours & $12.8(6.4-23.5)$ & $13.2(9.4-24.0)$ & ns \\
\hline \multicolumn{4}{|l|}{ Dosage of rivaroxaban in mg per day } \\
\hline $20 \mathrm{mg} / \mathrm{d}$ & $113(59.8 \%)$ & $36(69.2 \%)$ & \multirow[t]{5}{*}{ ns } \\
\hline $15 \mathrm{mg} / \mathrm{d}$ & $44(23.3 \%)$ & $7(13.5 \%)$ & \\
\hline $10 \mathrm{mg} / \mathrm{d}$ & $22(11.6 \%)$ & $6(11.5 \%)$ & \\
\hline $30 \mathrm{mg} / \mathrm{d}$ & $5(2.1 \%)$ & $1(1.9 \%)$ & \\
\hline Dosage unknown & $5(3.2 \%)$ & $2(3.8 \%)$ & \\
\hline \multicolumn{4}{|l|}{ Risk factors } \\
\hline Atrial fibrillation & $136(71.9 \%)$ & $41(78.8 \%)$ & ns \\
\hline Diabetes mellitus & $43(22.6 \%)$ & $11(21.2 \%)$ & ns \\
\hline Arterial hypertension & $152(80.4 \%)$ & $42(80.8 \%)$ & ns \\
\hline Hypercholesterolemia & $92(48.7 \%)$ & $11(21.2 \%)$ & $<.001$ \\
\hline Coronary artery disease & $40(21.2 \%)$ & $6(11.5 \%)$ & .06 \\
\hline \multicolumn{4}{|l|}{ Concomitant medication } \\
\hline Antiplatelets & $26(13.8 \%)$ & $5(9.6 \%)$ & ns \\
\hline Statins & $72(38.1 \%)$ & $10(19.2 \%)$ & .06 \\
\hline Antihypertensive agents & $146(77.2 \%)$ & $40(76.2 \%)$ & .042 \\
\hline \multicolumn{4}{|l|}{ Coagulation parameters } \\
\hline Rivaroxaban plasma levels & $82(30-202)$ & $102(51-165)$ & ns \\
\hline INR & $1.3(1.1-1.6)$ & $1.3(1.2-1.6)$ & ns \\
\hline Creatinin Clearence in $\mathrm{ml} / \mathrm{min}$ & $63(52-82)$ & $70(50-90)$ & ns \\
\hline
\end{tabular}

Continuous variables are given in median and interquartile range (IQR)

Categorical variables are given in number of patients and $\%$ 